Ardito C., Costabile M., De Marsico M., Lanzilotti R., Levialdi S., Plantamura P., Roselli T., Rossano V., Tersigni M. (2004). Towards Guidelines for Usability of eLearning Applications. In: C. Stary and C. Stephanidis eds. User-Centered Interaction Paradigms for Universal Access in the Information Society. (vol. LNCS 3196, pp. 185-202). Heidelberg: Springer-Verlag (Germany). ISBN: 978-3-540-23375-6.

\title{
Towards Guidelines for Usability of e-Learning Applications
}

\author{
C. Ardito*, M. F. Costabile*, M. De Marsico ${ }^{\circ}$, R. Lanzilotti*, S. Levialdi ${ }^{\circ}$, \\ P. Plantamura*, T. Roselli*, V. Rossano*, M. Tersigni ${ }^{\circ}$ \\ *Dipartimento di Informatica - Università di Bari \\ 'Dipartimento di Informatica - Università di Roma "La Sapienza" \\ \{ardito, costabile, lanzilotti, pplantamura, roselli, \\ rossano\}@di.uniba.it, \{demarsico, levialdi, \\ tersigni\}@di.uniromal. it
}

\begin{abstract}
One present goal of researchers and developers is to design software tools that make learning materials available online in an educationally effective manner. We face the twofold challenge of implementing advanced e-learning functionalities, though designing their interface so as to provide an easy interaction grasping the students' interest. A poorly designed interface makes students spend more time in learning it than in mastering the provided knowledge, so becoming a barrier to effective learning. In this context, both User-Centered Design (UCD) and Learner-Centered Design (LCD) guidelines are needed; it is also important to devise suited evaluation tools, able to help in identifying usability, and, more in general, accessibility flaws. Such tools must be designed bearing in mind the specific characteristics of e-learning applications. Traditional heuristic evaluation appears too general and subjective. In this paper, we propose a set of guidelines and criteria for elearning platforms (containers) and for educational modules (contents), to be used within the SUE (Systematic Usability Evaluation) inspection. We point out that human factors experts can primarily evaluate "syntactic" aspects of applications. Experts of education science and domain experts are to be involved for a more comprehensive evaluation.
\end{abstract}

\section{Introduction}

In the age of the new Information and Communication Technology, it should be possible to learn not only by a locally available electronic support, i.e. an interactive CD-Rom, but even "far away" from the teaching source. One challenge for designers and HCI researchers is to develop software tools able to engage novice learners and to support their learning even at distance. Aside from User-Centered Design (UCD) methods [7] for developing usable and accessible tools, we need Learner-Centered Design (LCD) methods [17] in order to make new learning domains accessible in an educationally effective manner. Because of the specific context in which an e-learning application is used, it is necessary to evaluate the application usability, but also the didactic effectiveness of the courseware. 
This kind of evaluation must be related to all aspects of didactic design of the courseware such as the analysis and definition of learning needs, the definition of learning goals, the methodology used for didactic content organization, and last but not least the selection and implementation of the learning assessment strategies. Thus, in the evaluation of an e-learning application it is important to involve both education science and domain experts with their own professional skills.

More questions arise depending on the new "vehicle" exploited in the learning process. Both content and teaching strategies must undergo re-purposing, in order to fully exploit the new technologies, adapting to each learner profile. We face a twofold challenge. Effective elearning applications should include advanced functions, yet their interface should hide their complexity to learners, providing an easy, flexible and satisfying interaction grasping the students' interest. Despite of this, what we often find is a mere electronic transposition of traditional material, provided through rigid interaction schemes and awkward interfaces.

The interaction between learners and computers is a neglected topic in the field of Web-based training. When learners complain about Web-based training or express a preference for classroom-based instruction, it's often not the training, but rather the confusing menus, unclear buttons, or illogical links that scare them off. The success of any training program is largely dependent on the student's motivation and attitude. If a poorly designed interface makes them feeling lost, confused, or frustrated, it will become a barrier to effective learning and information retention [10].

Accessibility is another neglected topic in the elearning context. Accessibility implies the requirement for access to information by individuals with different abilities, background and preferences, in a variety of contexts of use [23]. To deliver accessible elearning material, an opportunity worth exploring is personalization of digital material presentation in accordance with users' needs or preferences. Most of the existing efforts for supporting the preparation and delivery of accessible elearning material $[4,6,11]$ propose guidelines directed to technical accessibility aspects, such as the format and navigation of learning materials. Nevertheless, this approach does not take into account the didactic effectiveness of innovative e-learning methods for users with different abilities.

In this work, we argue that ensuring usability should be one of the main challenges of e-learning application developers, as well as a prerequisite that should allow learners to profitably exploit such applications. We also point out that computer scientists can primarily evaluate "syntactic" aspects of applications. Experts of education science and domain experts are to be involved for a more comprehensive evaluation. A cost-effective technique to evaluate usability is the heuristic evaluation originally proposed by Nielsen $[14,15]$. It prescribes to have a small set of experts inspecting the system, and evaluating its interface against a list of recognised usability principles - the heuristics. Experts can be usability specialists, experts of the specific domain of the application to be evaluated, or (preferably) double experts, with both usability and domain experience.

Heuristic evaluation has however a number of drawbacks. As highlighted in $[5,8$, 9], the major one is its high dependence upon the skills and experiences of the evaluators. Moreover heuristics, as formulated by Nielsen, are basically generic and unable to appropriately drive the evaluator's activity. This problem is pointed out by various researchers who have therefore developed more specific guidelines for 
particular system classes [1, 12, 23]. In order to provide a more robust evaluation method, SUE (Systematic Usability Evaluation) inspection has been introduced [13]. It uses evaluation patterns, called Abstract Tasks (ATs), describing how to estimate compliance of application components with a set of attributes and guidelines, which are preliminarily identified for a particular system class. ATs guide the inspector's activity, precisely describing which objects of the application to look for, and which actions to perform in order to analyse such objects. In this way, even less experienced evaluators are able to come out with more complete and precise results.

In this paper, we first dwell upon the difference between attributes for platforms (containers) and for educational modules (contents), provided by a platform or apart. We then propose a preliminary set of guidelines and criteria to be exploited for designing usable e-learning applications. More specifically, the paper is organized as follows. Section 2 describes the current scenario of usability of e-learning systems. Section 3 outlines the SUE inspection. In Section 4 we define usability guidelines for e-learning platforms and e-learning modules. E-learning usability evaluation is refined in Section 5 by giving a list of abstract Tasks to verify compliance with identified guidelines. Finally, Section 6 provides conclusions and highlights future works that will take into account the didactic effectiveness of e-learning applications.

\section{Usability Issues in e-Learning}

In any system, all the more if it is remote such as an e-learning system, usability plays a vital role for its success. If an e-learning system is not much usable, it obstructs the student's learning. So s/he is forced to spend much more time to understand software functionality, rather than to understand learning content. Moreover, if the e-learning interface is rigid, slow and unpleasant, people are just as like to go away and forget about it. As a matter of fact, one of the main goals of a learning system is to avoid any distraction to keep all the content fresh in learners' minds as they accommodate new and foreign concepts.

In the specific case of elearning, designing a "usable" interface means to put together interaction metaphors, images and concepts used to address functions and concepts on the screen in only one design, to create an interactive system that doesn't confuse learners.

A formative product should represent a rewarding experience for the learner. Norman [16] asserts that this kind of product should:

- be interactive and provide feedback

- have specific goals

- motivate, communicating a continuous sensation of challenge

- provide suitable tools

- avoid distractions and factors of nuisance interrupting the learning stream.

Moreover, it should be pedagogically suitable, though attractive and engaging. Using new technologies does not mean to reject traditional and successful teaching strategies, e.g. simulation systems, problem-based learning, and direct manipulation. So, a learning system should allow integrating such strategies. 
As already stated, a system providing new and flexible functionalities, supporting new strategies and allowing the integration with successful traditional techniques, could still suffer for poor usability. The need arises for a clear and coherent interface, able to involve the user in the learning process without overwhelming her/him. Forcing students to spend longer time understanding poorly usable interfaces than understanding learning content, is disruptive: distraction disturbs accommodation of new concepts and overall retention of what is being learnt. Learning interfaces have to give a comprehensive idea of content organization and of system functionalities, simple and efficient navigation, advanced personalization of contents and learning, clear exit. In other words, an efficient and motivating educational strategy must be devised and then suitably mapped onto an interface, concentrating on the needs and goals of the learners.

The key to develop a system conforming to the above usability criteria is to adopt a Learner-Centered (LC) methodology. Whereas User-Centered Design (UCD) assumes users' common culture and similar experiences in the application domain, in LCD a variety of learners' categories must be considered, because of personal learning strategies, different experience in the learning domain, different motivations in affording the learning task. In general, learners are not particularly experienced in the learning domain. In particular, they could not even know the learning domain they are approaching, or know it only partially, or even have a wrong idea of it. Moreover, students are not all stimulated by the same motivation in affording a task, rather, a student's motivation can be greatly influenced by the success rate experienced in learning; it will then be necessary to pay particular attention to aids that are provided (i.e. to the way scaffolding is managed) and to the acknowledgement of the improvements attained.

While for UCD the user's effort only concerns the comprehension of a new tool to perform a well known task, in LCD the gulf of expertise between the learner and the learning domain must be considered [17]. The goal of LCD can be defined as to fill up this gulf, making the learner acquire all the knowledge and tools connected to a given subject. In the case of LCD, then, we have to take the learner, through a tool s/he doesn't know how to use, to learn something s/he doesn't know: the problem doubles. Think for example of teaching a child to write using Microsoft Word.

Besides considering technological issues, it is necessary to rely on an educational theory somehow driving the designer in developing suitable tools. At present, constructivist theory is almost universally adopted. Learning is recognized as an active process, where "learning by doing" strategy takes the learner to cognitively manipulate the new learning material, to create cognitive links between it and prior knowledge. For this approach to be effective, a task must be always included in an actual and collaborative context, to make the learner understand the motivation and the final goal of the task itself, also by facing other learners' opinions (socioconstructivist principle) [22].

From all the previous considerations, it comes out that heuristics defined for UC (User-Centered) applications are not well suited to evaluate LC applications. The specific features required from elearning tools highlight the need to evaluate the usability of this kind of systems in a specific way. In fact, ensuring usability of elearning systems is an ongoing challenge for software developers. Various usability evaluation techniques exist, choosing among them is a trade-off between cost and 
effectiveness. Some methods, Ike heuristic evaluation, are easier to administer and less costly, but there are problems with using such method. These problems come from applying a small set of principles, the heuristics, to a wide range of systems. Indeed, generic guidelines are not readily applicable to all systems. This is pointed out by various researchers, who have then developed more specific guidelines for particular system classes [1, 12, 23]. For example, heuristics for the usability evaluation of groupware systems [1], and for systems with large display, as those used for fairs or other expositions 23], have been identified. It would be suitable to provide specific guidelines in order to evaluate usability of e-learning systems as well. In the next section, we describe our approach to the evaluation of usability through a technique that solves the drawbacks of heuristic evaluation, and systematizes the work of inspectors. We then present in the successive section a set of usability guidelines specifically defined for e-learning applications.

\section{The SUE Inspection}

Usability inspection refers to a set of methods through which evaluators examine usability-related aspects of an application and provide judgements based on their knowledge. With respect to other usability evaluation methods, such as user-based evaluation, usability inspection methods are more subjective. They are strongly dependent upon the inspector skills, and therefore it may happen that different inspectors produce non comparable outcomes. However, usability inspection methods "save users" [8], and do not require special equipment, nor lab facilities.

Examples of usability inspection methods are heuristic evaluation, cognitive walkthrough, guideline review, and formal usability inspection [15]. The most commonly used is heuristic evaluation [14, 15]. However, as highlighted in $[5,8,9]$, its major drawback is again its high dependence upon the skills and experiences of the evaluators. In order to overcome this problem, the SUE (Systematic Usability Evaluation) inspection technique has been introduced [13]. It uses evaluation patterns, called Abstract Tasks (ATs), for guiding the inspector's activity. ATs precisely describe which objects of the application to look for, and which actions the evaluators must perform in order to analyse such objects. In this way, also less experienced evaluators, with lack of expertise in usability and/or application domain, are able to come out whit more complete and precise results.

SUE inspection framework also provides a solution to the specialization of usability evaluation, mentioned in the previous section. To this aim, the framework provides a list of detailed heuristics that are specific for a class of applications. In the first place general usability principles are decomposed into finer-grained criteria, that can be better analysed. Then heuristics are obtained by specialising such criteria through usability attributes specific for the particular domain. In accordance with the suggestion given in [15], namely to develop category-specific heuristics, we have therefore defined a set of usability attributes, able to capture the peculiar features of elearning systems.

As stated above, ATs include a detailed description of the activities to be performed by evaluators during inspection [13], in order to detect possible violations 
of the identified heuristics. They are formulated precisely by means of a template providing a consistent format, that includes the following items:

- AT Classification Code and Title: univocally identify the AT, and succinctly convey its essence.

- Focus of Action: shortly describes the context, or focus, of the AT, by listing the application components that are the evaluation entities.

- Intent: describes the problem addressed by the AT and its rationale, trying to make clear which is the specific goal to be achieved through the AT application.

- Activity Description: describes in detail the activities to be performed during the AT application.

- Output: describes the output of the fragment of the inspection the AT refers to.

During the inspection, evaluators analyse the application. During this activity, the different application components, i.e., the objects on which the evaluation must focus on, are identified. Then, having in mind the usability criteria, evaluators apply ATs and produce a report in which the discovered problems are described. The list of ATs provides a systematic guidance to the evaluator on how to inspect an application. Most evaluators are very good in analysing only certain features of interactive applications; however, they often neglect some other features, strictly dependent on the specific application category. Exploiting a set of ATs ready for use allows evaluators with no experience in a particular domain to perform a more accurate evaluation.

We have identified a set of usability attributes and guidelines, able to capture the peculiar features of elearning applications. According to the SUE inspection, from these usability attributes and guidelines we have derived the ATs for evaluating such applications.

\section{Usability Evaluation of e-Learning Applications}

While defining usability attributes for e-learning, it is first of all necessary to dwell upon the difference between an e-learning platform (container) and educational modules provided by a platform or even apart (content). In particular, an e-learning platform is a more or less complex environment with a number of integrated tools and services for teaching, learning, communicating and for learning material management. Usability attributes for this environment generally differ from those that can be identified for a specific e-learning product considered as an educational module. These two classes of software artefacts must be approached in parallel and independently, since different features must be considered. However, as we will see later, it is true that some characteristics of the e-learning module provided through a platform are bound to functionalities of the platform itself.

In identifying criteria and attributes for evaluating e-learning tools, we must consider the peculiarity of e-learning, whose primary goal is to allow students to learn the didactic material by devoting the minimum effort to the interaction with the system. The work reported in this paper is grounded on our experience in developing 
e-learning applications targeted to different types of users [2, 3, 19, 20, 21]. Moreover, we have performed various studies. We have considered recent literature (for sake of space we cannot quote all the interesting material, but see for example ACM E-Learn Magazine, http://www.elearnmag.org/), and performed cognitive walkthrough for a number of distance courses available in currently used platforms. Nevertheless, as for other classes of applications, users' feedback is the most valuable tool to find out problems. For this reason we have also adopted the thinking aloud technique in an experimental study that involved ten post-graduated students of a Master course at the University of Bari, Italy. It is worth summarizing the obtained results. Students were asked to interact with a DL (Distance Learning) system. Their objective was to learn some new topics by using only the system via Internet. A number of communication tools allowed to exchange information, to ask help and to suggest solutions. Then, interviews were carried out for gathering further information from these students. The basic questions concerned the kind of difficulties met, best ways to organize educational material and services, opinions about the communication tools used (forum, chat, mail).

Both thinking aloud and interviews highlighted a number of problems. A major number of participants experienced disorientation and often reported bewilderment and difficulty to proceed, particularly when following a new learning path or using a service for the first time. Moreover, a number of users complained about the lack of mechanisms to highlight both lesson structure and high priority topics, in particular those scheduled for a particular learning session. Actually, a lot of participants linked to a wrong didactic unit. It comes out that learning material presentation, providing a consistent visual conceptual map for easy navigation, is a relevant aspect for e learning system usability. It would also be suitable to allow a personalized access to the content. Participants also reported problems searching the educational material to study. Search for documents should instead be facilitated, e.g. by a clear specification of key-words for each subject.

A number of participants showed frustration when they had to start from the beginning due to network temporary disconnection. Therefore, a number of comments stated that it should be possible to use the platform even offline, preserving the reached educational context.

Self-assessment allowed the participants to control their progresses, and this was found very motivating. Participants also expressed a positive opinion on the communication tools, allowing collaborative learning: these tools permit managing of the teaching process for one or more learners, through synchronous and asynchronous interactions.

The overall study confirmed that e-learning usability is a very complex issue. We have to consider presentation aspects, in particular cues helping learning. Moreover, the presence of hypermedia tools requires the possibility to personalize the reading path and the communication through different channels, still permitting orientation. Finally, user's initiative should be encouraged: the participants preferred selfassessment tests to evaluate their progress. The above aspects are related not only to the e-learning environment, but also to the structure of the educational material.

Following our preliminary studies, we have identified four dimensions for our analysis: 
A. Presentation encompasses exterior features of the interface, highlighting possibilities and tools provided by the platform or by the educational module.

B. Hypermediality considers aspects bound to the communication through different channels and following a possibly non-sequential structure, stressing the analysis and the personalization of reading paths.

C. Application proactivity takes into account mechanisms and modalities through which the system supports the learner's training, and activities proposed.

D. User's activity is focused on learner's rising needs, i.e. on unplanned activities s/he would want to perform, and on how the system copes with them.

We will refer to effectiveness and efficiency as general principles to evaluate each dimension. We relay on ISO definition for such principles. According to [ISO98], usability is defined as the "extent to which a product can be used by specified users to achieve specified goals with effectiveness, efficiency and satisfaction in a specified context of use". Effectiveness is defined as the "accuracy and completeness with which users achieve specified goals". In our case, we consider goals related to learning tasks. Efficiency is defined as the "resources expended in relation to the accuracy and completeness with which users achieve goals". We are especially interested in user's efforts required to achieve learning goals. The aim of an e-learning application should be to facilitate the user in grasping new concepts, by not overwhelming her/him with usage difficulties of the application itself while highlighting the conceptual structure and links of the subject at hand. General principles are further divided in criteria, how we shall describe in the following.

In Sections 4.1 and 4.3 we further discuss the four analysis dimensions, considering respectively e-learning platforms and modules, while in Sections 4.2 and 4.4 we propose the corresponding evaluation criteria along the four dimensions.

\subsection{Usability Dimensions for e-Learning Platforms}

In the following, we detail elements referred by each dimension for evaluating an elearning platform.

\section{Presentation dimension}

This dimension concerns all aspects bound to the visual design of tools and elements that set up the e-learning platform. To avoid confusion in interpreting the meaning of this dimension, it is necessary to consider that in this context we only analyze mere visualization. Actually, we ought not to confuse visualization of platform elements, discussed in this dimension, with their structuring and modelling, which pertain to other dimensions. In particular, as regards progress tracking, its clear and understandable visualization is an Efficiency parameter in this dimension, as the actions of the student wanting to verify her/his learning state are simplified; on the other hand, the presence of this element in itself, is an Effectiveness parameter in the Application Proactivity dimension, because learning could result less effective without an overview of student's results and gaps. The same holds for the state of the 
system. On the one end, its constant visualization is an Efficiency parameter in this dimension, facilitating student's movements; on the other end the presence of this element in itself is an Effectiveness parameter in Hypermediality dimension, as orienting oneself in the context of course subjects helps creating a mental map of the discourse and facilitates understanding and memorization.

It is in the Presentation dimension that we consider the issue of the clarity of presentation of platform tools. It is necessary that the possibilities they provide to users be clear and that errors made using them be highlighted, when not avoided.

It is also important that the student can easily identify in which part of the course s/he is at present, and how to reach a different one. To this aim, course structure should be visualized in a way allowing orientation and easy move among subjects (i.e. through a map or a representation based on the folder metaphor).

As it concerns access technology, this is an issue common with Application Proactivity dimension, and is here considered only from the graphical aspect point of view. For example, it would be necessary to consider that if one wants to access the platform from a palmtop computer, layout of elements on the screen must adapt to its reduced size.

\section{Hypermediality dimension}

If we consider hypermediality from the point of a view of a platform, the presence of hypermedia tools surely appears as a further possibility provided to lecturers and students. As it will be discussed later, this could not be true when evaluating how contents are structured inside single educational modules.

Hypermediality allows to communicate through different channels (audio, video, textual) but even to organize lessons in a not necessarily sequential way, also allowing a student to choose a personalized logical path different from the one suggested by the lecturer. It is just in connection with hypermediality that the student should have no difficulty in orienting herself/himself in the course organization, as discussed with regard to Presentation dimension.

Hypermediality contribute is significant to the achievement of learning. Moreover, it is desirable the possibility to insert one's own links (bookmarks) allowing to further increase flexibility of content organization. To this respect, it is important to notice the poor learning value of non-contextual links, which save references to target pages and documents without reference to the source point, i.e. to the point from which the link conceptually starts. After a small amount of time the student would forget her/his aim when creating such a link: in an educational context, information acquires and maintains meaning just from its framework. Such framework should be maintained even in off-line access: it is not desirable the student be forced to be connected to the network along all her/his learning time.

\section{Application Proactivity dimension}

In defining attributes for this dimension, we tried to follow principles of the socioconstructivistic approach, the educational theory most reliable nowadays. This approach, for example, takes to require from the platform spaces for inserting tools of the learning domain. Such tools should be embedded as much as possible in an actual context of use.

In this dimension we consider platform tools related to learning activities, in particular planned ones. Ease of use of such tools is an aspect to consider in all UCD 
systems. Nevertheless, it gains an even greater importance in LCD systems, where the user just makes an effort consisting in learning, which is the primary goal. The same considerations take to require that student's errors in using the platform tools should be prevented as much as possible. However, we have not to confuse simplification in the interface with oversimplification in the proposed contents and tasks. Ease of use and error prevention do not apply to the activities performed through the tools strictly bound to learning, in particular the learning domain tools, and to students' assessment tests. Rather, the latter category of errors provides a further learning occasion if they are highlighted by the platform, e.g using graphics (as discussed with regard to Presentation dimension), if places for explanations are provided, and if lnks to scarcely mastered parts of the course are automatically suggested.

In the case of complex tasks, novice learners should be rather supported in their first approach. Specific tools provided to this aim set up scaffolding activities. An effective scaffolding should be gradually attenuated as student proceeds in learning. We have to consider how such attenuation has to be managed: the lecturer should be able to delegate this task to specific platform automatic mechanisms.

As any other multi-user system, an e-learning platform must allow access to different users' classes. Each of them will hold a specific role inside the educational process: lecturer, student, tutor, and administrator. The platform should then allow to define different typologies of profiles and correspondently provide different views and capabilities. These considerations apply specifically to the repository: lecturers and students are two actors bearing different characteristics and needs, and so different access modes to the repository. Moreover, we have to consider the different languages used by the two figures, which is more appropriate for the lecturer and less precise for the student; the platform should so provide different searching modalities.

\section{User's Activity dimension}

In this dimension we consider all needs of a student/lecturer choosing to learn/teach at a distance and platform tools (e.g. communication tools) not strictly related to planned learning activities. Student's needs are to be able to make assessment tests and to check her/his progress at any time, even when not proposed by the platform, and to annotate and integrate the learning material provided with her/his own documents, autonomously collected. Moreover, the possibility to personalize scaffolding attenuation must be provided, in order to efficiently cope with the two symmetrical situations of a student needing supplementary scaffolding, or needing less of it.

Lecturer's needs must also be considered: for example, even if not possible to evaluate student's engagement merely from observation of her/his activities, it is anyway very useful for the lecturer to have a detailed report from which to verify how much and how her/his course is exploited by students. This could help to understand if the organization chosen needs some update or change, if it is appreciated or not and which problems the students encounter.

\subsection{Usability Criteria and Guidelines for e-Learning Platforms}

For each dimension we considered the general principles of effectiveness and efficiency that contribute to characterize usability [7], dividing them in criteria: 


\section{Effectiveness:}

Supportiveness for Learning/Authoring: how the tools provided by the platform allow to learn and prepare lessons in an effective way.

Supportiveness for communication, personalization and access: how the provided tools satisfy these needs greatly influences the learning effectiveness.

Efficiency:

Structure adequacy: how efficiently the activities the user usually performs are structured and visualized.

Facilities and technology adequacy: efficiency of scaffolding and supplementary supports provided to the user; how the platform adapts to the technology used by the learner to access it.

From the above criteria, a first set of guidelines are derived, as reported in Table 1.

\begin{tabular}{|c|c|c|c|}
\hline Dimensions & $\begin{array}{c}\text { General } \\
\text { principles }\end{array}$ & Criteria & Guidelines \\
\hline \multirow{8}{*}{ Presentation } & \multirow{3}{*}{ Effectiveness } & \multirow{2}{*}{$\begin{array}{l}\text { Supportiveness for } \\
\text { Learning/Authoring }\end{array}$} & $\begin{array}{l}\text { For interface graphical aspects, the same } \\
\text { UCD attributes hold }\end{array}$ \\
\hline & & & \begin{tabular}{|l}
$\begin{array}{l}\text { Errors and cues to avoidance are } \\
\text { highlighted }\end{array}$ \\
\end{tabular} \\
\hline & & $\begin{array}{c}\text { Supportiveness for } \\
\text { communication, } \\
\text { personalization and } \\
\text { access }\end{array}$ & $\begin{array}{l}\text { It is possible to personalize interface } \\
\text { graphics }\end{array}$ \\
\hline & \multirow{5}{*}{ Efficiency } & \multirow{4}{*}{ Structure adequacy } & $\begin{array}{l}\text { System state is clearly and constantly } \\
\text { indicated }\end{array}$ \\
\hline & & & Progress tracking is clearly visualized \\
\hline & & & $\begin{array}{l}\text { Possibilities and commands available are } \\
\text { clearly visualized }\end{array}$ \\
\hline & & & Course structure is clearly visualized \\
\hline & & \begin{tabular}{|c|} 
Facilities and \\
technology adequacy
\end{tabular} & $\begin{array}{l}\text { Adaptation of the graphical aspect to the } \\
\text { context of use is provided }\end{array}$ \\
\hline \multirow{7}{*}{ Hypermediality } & \multirow{4}{*}{ Effectiveness } & \multirow{2}{*}{$\begin{array}{l}\text { Supportiveness for } \\
\text { Learning/Authoring }\end{array}$} & $\begin{array}{l}\text { The lecturer is supported in preparing } \\
\text { multimedia material }\end{array}$ \\
\hline & & & $\begin{array}{l}\text { Easy movement among subjects is } \\
\text { allowed by highlighting cross-references } \\
\text { through state and course maps }\end{array}$ \\
\hline & & \multirow{2}{*}{$\begin{array}{c}\text { Supportiveness for } \\
\text { communication, } \\
\text { personalization and } \\
\text { access }\end{array}$} & \begin{tabular}{|l|l|} 
Communication is possible through \\
different media channels
\end{tabular} \\
\hline & & & \begin{tabular}{|l|l|} 
A personalized access to learning \\
contents is possible
\end{tabular} \\
\hline & \multirow{3}{*}{ Efficiency } & $\begin{array}{c}\text { Structure } \\
\text { adequacy }\end{array}$ & $\begin{array}{l}\text { Both lecturer and student can access the } \\
\text { repository }\end{array}$ \\
\hline & & \multirow{2}{*}{$\begin{array}{c}\text { Facilities and } \\
\text { technology adequacy }\end{array}$} & $\begin{array}{l}\text { It is possible to create contextualized } \\
\text { bookmarks }\end{array}$ \\
\hline & & & $\begin{array}{l}\text { The platform can be used off-line, } \\
\text { maintaining tools and learning context }\end{array}$ \\
\hline
\end{tabular}

Table 1. Usability Criteria and Guidelines for e-Learning Platforms 


\begin{tabular}{|c|c|c|c|}
\hline Dimensions & $\begin{array}{l}\text { General } \\
\text { principles }\end{array}$ & Criteria & Guidelines \\
\hline \multirow{10}{*}{$\begin{array}{l}\text { Application } \\
\text { Proactivity }\end{array}$} & \multirow{4}{*}{ Effectivenes s } & \multirow{3}{*}{$\begin{array}{l}\text { Supportiveness for } \\
\text { Learning/Authoring }\end{array}$} & $\begin{array}{l}\text { It is possible to insert assessment } \\
\text { tests in various forms }\end{array}$ \\
\hline & & & \begin{tabular}{|lcc} 
Platform & automatically & updates \\
students' progress tracking
\end{tabular} \\
\hline & & & $\begin{array}{l}\text { Platform allows to insert learning } \\
\text { domain tools }\end{array}$ \\
\hline & & $\begin{array}{c}\text { Supportiveness for } \\
\text { communication, } \\
\text { personalization and access }\end{array}$ & Users profiles are managed \\
\hline & \multirow{6}{*}{ Efficiency } & \multirow{4}{*}{ Structure adequacy } & $\begin{array}{l}\text { Mechanisms exist to prevent usage } \\
\text { errors }\end{array}$ \\
\hline & & & $\begin{array}{l}\begin{array}{l}\text { Mechanisms exist for teaching- } \\
\text { through-errors }\end{array} \\
\text { ther }\end{array}$ \\
\hline & & & $\begin{array}{l}\text { Lecturer and students access the } \\
\text { repository in different modes }\end{array}$ \\
\hline & & & Platform tools are easy to use \\
\hline & & \multirow{2}{*}{$\begin{array}{l}\text { Facilities and technology } \\
\text { adequacy }\end{array}$} & $\begin{array}{l}\text { Adaptation of technology to the } \\
\text { context of use is provided }\end{array}$ \\
\hline & & & $\begin{array}{l}\text { The date of last modification of } \\
\text { documents is registered in order to } \\
\text { facilitate updating }\end{array}$ \\
\hline \multirow{11}{*}{$\begin{array}{l}\text { User's } \\
\text { Activity }\end{array}$} & \multirow{8}{*}{ Effectiveness } & \multirow{4}{*}{$\begin{array}{l}\text { Supportiveness for } \\
\text { Learning/Authoring }\end{array}$} & $\begin{array}{l}\text { Easy-to-use authoring tools are } \\
\text { provided }\end{array}$ \\
\hline & & & $\begin{array}{l}\text { Assessment tests to check one's } \\
\text { progress at any time are provided }\end{array}$ \\
\hline & & & $\begin{array}{l}\text { Reports are managed about } \\
\text { attendance and usage of a course }\end{array}$ \\
\hline & & & $\begin{array}{l}\text { It is possible to use learning tools } \\
\text { even when not scheduled }\end{array}$ \\
\hline & & \multirow{4}{*}{$\begin{array}{c}\text { Supportiveness for } \\
\text { communication, } \\
\text { personalization and access }\end{array}$} & $\begin{array}{l}\text { Both synchronous and asynchronous } \\
\text { communication tools are provided }\end{array}$ \\
\hline & & & $\begin{array}{l}\text { It is possible to communicate with } \\
\text { both students and lecturers }\end{array}$ \\
\hline & & & It is possible to make annotations \\
\hline & & & \begin{tabular}{|l} 
It is possible to integrate the \\
provided material
\end{tabular} \\
\hline & \multirow{3}{*}{ Efficiency } & Structure adequacy & $\begin{array}{l}\text { Mechanisms are provided for search } \\
\text { by indexing, key or natural language }\end{array}$ \\
\hline & & \multirow{2}{*}{$\begin{array}{l}\text { Facilities and technology } \\
\text { adequacy }\end{array}$} & $\begin{array}{l}\text { Authoring tools allow to create } \\
\text { standard-compliant documents and } \\
\text { tests (AICC, IMS, SCORM) }\end{array}$ \\
\hline & & & $\begin{array}{l}\text { Authoring tools facilitate documents } \\
\text { update and assessment tests editing }\end{array}$ \\
\hline
\end{tabular}

Table 1 Continued. Usability Criteria and Guidelines for e-Learning Platforms 


\subsection{Usability Dimensions for e-Learning Modules}

In the following, we specialize each dimension for evaluating an e-learning module.

Presentation dimension

This dimension regards the way the lecturer decides to make visualized both lessons and supports to the students (scaffolding) s/he has prepared. A new lesson or an updated one, belonging to the same subject or course, should have the same layout, both for the graphical aspect and content organization.

As reading appears to be more tiring during prolonged interaction with the e learning system through video, it is opportune to concentrate more important contents at the beginning, eventually highlighting their priority through graphical cues. Even the hierarchical structure of subjects must be highlighted: this is very effective both from the conceptual point of view and to exploit and stimulate student's visual memory.

\section{Hypermediality dimension}

Hypermedia tools are one of the major differences among in-presence (classical model) and on-line education. On the one hand, such tools can be surely considered an advantage. Nevertheless, if misused, they burden the student, instead of facilitating her/him. This happens if sensory channels (sight, hearing, hands) are overloaded, also considering that the student is not expert of the learning domain. For example, auditory and textual channels should not be overlapped: this would take to a symbolic memory overload, unless audio and text are strictly related, as in the case of a sound attracting attention on a particular text message.

Moreover, it is good practice not to overuse hypertextual and/or hypermedial links, as a link causes a change in what the student visualizes. Such changes could bewilder the student, taking to a problem which is common on the web, i.e. to be "lost in hyperspace".

Even if multiple communication and presentation media are provided, one has to carefully choose those more suited to the learning goal, or even to the particular learning domain.

Finally, in order to facilitate both lecture editing and in-depth study, it is necessary that the learning materials be reusable even in contexts different from those for which they have initially been conceived (i.e., they might be used as a deeper insight for one course or as a base subject for a different course).

Application Proactivity dimension

In this dimension, value of teaching is found in the ability to propose activities, as the use of learning domain tools, capable to form in an effective and efficacious way. One of the principles of socio-constructivistic theory is that learning mainly occurs in an environment where tools reflect the actual context of use: the learning domain must be introduced without oversimplifications since the beginning, eventually providing scaffolding; the student will "learn by doing", and making errors, in order to also awake her/his hidden knowledge. To this aim, it is important that assessment tests be organized in such a way to represent deep-insight occasions for the student. A good tool does not limit itself to make the student realize the error, but explains the cause and helps to focus on key-issues of the subject at hand. 
A further evaluation parameter is represented by scaffolding organization. In defining scaffolding, presence and attenuation must be carefully considered. As regards presence, we are in the LCD context: differently from UCD, and regarding learning content, the aim is not to minimize the cognitive effort (for example, through a massive use of scaffolding). On the contrary, this must be stimulated, such that learner's activity is not flattened and oversimplified, with the consequence of diminishing learning persistence. As regards scaffolding attenuation, there are still a number of open questions: Who should attenuate scaffolding? The student, based on her/his needs, or the lecturer, based on the provided learning plan? Is it appropriate to assign this task to the system, which will perform it in an automatic way? Which is the speed at which scaffolding must attenuate? For the time being, each specific situation should be analysed in itself. It would not be significant to define general rules encompassing all cases.

\section{User's Activity dimension}

Here we analyse activities which the student could need to perform, even when not suggested by the module according to the lecturer provided plan. Examples of such needs are customizing media channels, searching from the repository through a careful identification of key-words of each subject, creating personal paths or performing assessment tests when needed.

Moreover, the student could "miss" the traditional in-presence lesson. Choosing to teach through e-learning does not mean to reject in toto traditional teaching, rather it seems better to merge on-line learning with "actually" shared moments. If logistic reasons make this unfeasible, it will be necessary to try to reproduce such situations at one's best, e.g. by a video/audio synchronous communication and shared boards.

\subsection{Usability Criteria and Guidelines for e-Learning Modules}

In this context, for each dimension we have considered the criteria of effectiveness of teaching/authoring and of efficiency of supports and teaching modalities. Criteria and guidelines referring to them are reported in Table 2.

\section{SUE Inspection for e-Learning Applications}

As we said in Section 3, SUE inspection is based on the use of Abstract Tasks to drive the evaluators' activities. By taking into account the usability attributes and the guidelines reported in Tables 1 and 2, we have derived some ATs that support the inspector in the evaluation of specific components of e-learning applications. 


\begin{tabular}{|c|c|c|}
\hline Dimensions & Criteria & Guidelines \\
\hline \multirow{5}{*}{ Presentation } & \multirow{4}{*}{$\begin{array}{l}\text { Effectiveness of } \\
\text { teaching/authoring }\end{array}$} & Content update is consistent \\
\hline & & High priority subjects are highlighted \\
\hline & & $\begin{array}{l}\text { Graphic layout does not distract the learner but } \\
\text { helps him/her in learning }\end{array}$ \\
\hline & & $\begin{array}{llll}\begin{array}{l}\text { Hierarchical structure of course subjects is } \\
\text { highlighted }\end{array} & & \\
\end{array}$ \\
\hline & $\begin{array}{c}\text { Efficiency of supports } \\
\text { and teaching } \\
\text { modalities }\end{array}$ & $\begin{array}{l}\text { Scaffolding are assigned a non-invasive space to } \\
\text { not distract the learner }\end{array}$ \\
\hline \multirow{5}{*}{ Hypermediality } & \multirow{2}{*}{$\begin{array}{l}\text { Effectiveness of } \\
\text { teaching/authoring }\end{array}$} & $\begin{array}{l}\text { Used tools are able to plunge the learner in the } \\
\text { learning domain context }\end{array}$ \\
\hline & & $\begin{array}{l}\text { Specific communication media are used for each } \\
\text { subject and learning goal }\end{array}$ \\
\hline & \multirow{3}{*}{$\begin{array}{c}\text { Efficiency of supports } \\
\text { and teaching } \\
\text { modalities }\end{array}$} & $\begin{array}{l}\text { Communication channels are used in an optimal } \\
\text { way }\end{array}$ \\
\hline & & $\begin{array}{l}\text { Hypertextual and hypermedial links are carefully } \\
\text { used }\end{array}$ \\
\hline & & Learning material can be reused and integrated \\
\hline \multirow{5}{*}{$\begin{array}{l}\text { Application } \\
\text { Proactivity }\end{array}$} & \multirow{3}{*}{$\begin{array}{l}\text { Effectiveness of } \\
\text { teaching/authoring }\end{array}$} & Specific learning domain tools are provided \\
\hline & & $\begin{array}{l}\text { The help and number of scaffolding are carefully } \\
\text { chosen }\end{array}$ \\
\hline & & Testing tools are reliable \\
\hline & \multirow{2}{*}{$\begin{array}{l}\text { Efficiency of supports } \\
\text { and teaching } \\
\text { modalities }\end{array}$} & $\begin{array}{l}\text { Scaffolding is correctly attenuated (if attenuation } \\
\text { is driven by the lecturer) }\end{array}$ \\
\hline & & $\begin{array}{l}\text { The document formats used do not require } \\
\text { specific plug-ins }\end{array}$ \\
\hline \multirow{3}{*}{ User's Activity } & \multirow{2}{*}{$\begin{array}{l}\text { Effectiveness of } \\
\text { teaching/authoring }\end{array}$} & $\begin{array}{l}\text { It is possible to limit or choose the media } \\
\text { channels }\end{array}$ \\
\hline & & Blended-learning simulations are provided \\
\hline & $\begin{array}{c}\text { Efficiency of supports } \\
\text { and teaching } \\
\text { modalities }\end{array}$ & $\begin{array}{l}\text { Search for documents is facilitated by a correct } \\
\text { and clear specification of key-words }\end{array}$ \\
\hline
\end{tabular}

Table 2. Usability Criteria and Guidelines for e-Learning Modules

Specifically, these ATs are grouped in the following categories (see also Table 3):

(1) Content insertion and content access: this category includes ATs to evaluate tools that permit and facilitate authoring and permit content search.

(2) Scaffolding: this category includes ATs to evaluate mechanisms that support the user in harder tasks.

(3) Learning Window: this category includes ATs to evaluate the features of the virtual environment for learning, i.e. where the student works, studies, and verifies her/his learning level.

ATs are distinguished in basic and advanced (AT TYPE column in Table 3); the former are took into consideration during a less specific evaluation: their aim is to give the evaluator a first insight of the system functionalities. Advanced ATs, instead, are used for a more detailed analysis of the characteristics to evaluate. In the last 
column in Table 3, we indicate $\mathrm{P}$ if the AT is defined to evaluate features of the Platform, $\mathrm{M}$ if it addresses features of the e-learning Modules.

\begin{tabular}{|c|c|c|c|}
\hline AT CATEGORY & AT TYPE & AT CODE AND TITLE & \\
\hline \multirow{5}{*}{$\begin{array}{l}\text { Content insertion } \\
\text { and content access }\end{array}$} & \multirow[b]{2}{*}{ basic } & C_1: check of authoring tools & $\overline{\mathrm{P}}$ \\
\hline & & $\begin{array}{l}\text { C_2: check of the window for requests to } \\
\text { repository }\end{array}$ & $\mathrm{P}$ \\
\hline & \multirow{3}{*}{ advanced } & C_3: reuse verification & $\overline{\mathrm{M}}$ \\
\hline & & C_4: check of the different access modalities & $\overline{\mathrm{P}}$ \\
\hline & & C_5: check for support to authoring & $\mathrm{P}$ \\
\hline \multirow{4}{*}{ Scaffolding } & \multirow{2}{*}{ basic } & S_1: help verification & $\bar{M}$ \\
\hline & & S_2: graphic layout & M \\
\hline & \multirow{2}{*}{ advanced } & S_3: check of attenuation & P/M \\
\hline & & S_4: check of presence & $\mathrm{M}$ \\
\hline \multirow{8}{*}{ Learning Window } & \multirow{2}{*}{ basic } & LW_1: organization of a course document & $\mathrm{M}$ \\
\hline & & LW_2: fruition of a course document & $\mathrm{P} / \mathrm{M}$ \\
\hline & \multirow{6}{*}{ advanced } & LW_3: check of assessment testing & P/M \\
\hline & & LW_4: check of communication tools & $\mathrm{P}$ \\
\hline & & LW_5: usage of communication tools & $\mathrm{M}$ \\
\hline & & LW_6: check of learning domain tools & $\mathrm{P}$ \\
\hline & & LW_7: adequacy of learning domain tools & $\mathrm{M}$ \\
\hline & & LW_8: advanced personalization verification & $\bar{P}$ \\
\hline
\end{tabular}

Table 3. Some ATs for Inspecting e-Learning Applications

In the following, we report two examples of ATs to evaluate the fruition of a course document: the first refers to the platform aspects $(\mathrm{P})$, the latter to modules $(\mathrm{M})$. The ATs are defined according to the template indicated in Section 3.

\section{LW 2 (P): fruition of a course document}

Focus of action: learning window

Intent: to evaluate modalities, commands, and any mechanisms to access course documents.

Activity description: given a learning window:

- $\quad$ execute commands to move among the course documents

- execute commands to move among the topics of different courses

- $\quad$ access offline to the document

Output: a description reporting if:

- a personalized content fruition is possible (e.g. modifying a predefined path, through a course map, etc.)

- an interdisciplinary content fruition is possible

- the system status and the student position in the course are always indicated

- $\quad$ it is possible to use the commands to move among courses and topics without leaving the learning environment

- the offline access to document is possible without loosing the learning context. 


\section{LW 2 (M): fruition of a course document}

Focus of action: learning window

Intent: to evaluate modalities, commands, and tools to access to course documents. Activity description: given a learning window:

- $\quad$ explore a document following different logic learning paths

- $\quad$ open some documents to identify the required plug-ins

Output: a list reporting if:

- the documents structure permits different personalized learning paths

- $\quad$ specific plug-ins are necessary

\section{Conclusions and Future Work}

We have discussed issues related to the evaluation of e-learning systems. We have defined a set of usability criteria that capture some features of this kind of applications. We have also proposed how to adapt to the e-learning domain the SUE inspection technique, which uses evaluation patterns (Abstract Tasks), to drive the inspectors' activities. We have not performed yet an experimental comparison with traditional heuristics, even because we are still refining the set of ATs, but we expect results similar to those presented in [Mat02].

It is worth mentioning that, as human factor experts, we can only evaluate "syntactic" aspects of elearning applications. In order to go deeply into aspects concerning pedagogical approach and content semantics, experts of education science and domain experts are to be involved. The evaluation from a pedagogical point of view concerns, for instance, the coherence and the congruence of the learning path design. More specifically, the following must be evaluated:

A. the analysis of learning needs: in designing the courseware, has a detailed analysis of the learning needs been performed?

B. definition of learning goals: are the learning goals well-organized in terms of cognitive and metacognitive abilities that the learners have to acquire?

C. selection of the teaching methodologies: is the teaching methodology selected during the design phase appropriately implemented?

D. didactic content organization: is the organization of didactic resources consistent with the organization of defined learning goals?

E. learning assessment: are the assessment methods and tools suited for the courseware?

These are the issues we are currently exploring in order to perform a nore comprehensive evaluation. We are aware of the difficulties of this objective. However, we hope that the synergy with education experts will allow us to possibly identify specific guidelines for didactic effectiveness to be included in our general evaluation framework.

Finally, another important objective is to evaluate accessibility. Guidelines in literature usually provide high-level/generic indications on alternative forms of didactic content to enable access to it by people with different abilities. Further 
research is necessary in order to identify techniques and tools to evaluate if the application is not only accessible but usable and didactically effective for the learners.

\section{Aknowledgments}

The financial support of Italian MIUR through VICE and WEB-MINDS projects is aknowledged.

\section{References}

1. Baker, K., Greenberg, S., and Gutwin, C., Empirical Development of a Heuristics Evaluation Methodology for Shared Workspace Groupware. In Proceedings of the ACM Conference on Computer Supported Cooperative Work (CSCW '02) (New Orleans, Lousiana, USA, November 16-20, 2002), 2002, 96-105.

2. Costabile, M.F., De Angeli, A., Roselli, T., Lanzilotti, R., Plantamura, P., Evaluating the Educational Impact of a Tutoring Hypermedia for Children, Information Technology in Childhood Educational Annual, 2003, 289-308.

3. Costabile, M.F., De Angeli, A., Roselli, T., Lanzilotti, R., Plantamura, P., Does Hypermedia Really Work for Tutoring Children?, IEEE Multimedia, vol. April-June 2003, 65-69

4. CPB/WGBH National Center for Accessible Media (NCAM) http://ncam.wgbh.org/cdrom/guideline/

5. Doubleday, A., Ryan, M., Springett, M., and Sutcliffe, A., A Comparison of Usability Techniques for Evaluating Design. In Proceedings of DIS'97, (Amsterdam, NL. August 1997). ACM Press, 1997, 101-110.

6. IMS Guidelines for Developing Accessible Learning Applications, Versione 1.0, White Paper, 2002. http://www.imsproject.org/accessibility/

7. ISO 9241: Ergonomics Requirements for Office Work with Visual Display Terminal (VDT), 1998.

8. Jeffriess, R., Miller, J., Wharton, C., and Uyeda, K.M., User Interface Evaluation in the real world: a comparison of four techniques. In Proceedings of CHI'91, (New Orleans, LA, USA, 1991), ACM Press, 1991, 119-124.

9. Kantner, L., and Rosenbaum, S., Usability Studies of WWW sites: Heuristic Evaluation vs Laboratory Testing. In Proceedings of SIGDOC'97, (Snowbird, UT, USA, 1997), ACM Press, 1997, 153-160.

10. Kruse, K. (May, 2000). Web rules: effective user interface design. http://www.learningcircuits.org/may2000/may2000_webrules.html.

11. The Learning Federation http://www.thelearningfederation.edu.au/repo

12. Mankoff, J., Dey, A., Hsieh, G., Kients, J., Lederer, S., and Ames, M., Heuristic Evaluation of Ambient Display. In Proceedings of ACM Conference on Human Factors and Computing Systems, (CHI '03), (Ft. Lauderdale, FL, USA, April 5-10, 2003). 2003, 169-176.

13. Matera, M., Costabile, M.F., Garzotto, F., and Paolini, P., SUE Inspection: an Effective Method for Systematic Usability Evaluation of Hypermedia. IEEE Transactions on Systems, Man and Cybvernetics- Part A, 32, 1, 2002, 93-103.

14. Nielsen, J., Usability Engineering. Academic Press. Cambridge, MA, 1993. 
15. Nielsen, J. and Mack, R.L., Usability Inspection Methods. John Wiley \& Sons, New York, 1994.

16. Norman, D., Things That Make us Smart: Defending Human Attributes in the Age of the Machine, Perseus Publishing, Cambridge:MA, 1993

17. Quintana, C., Carra, A., Krajcik, J., and Elliot, S., Learner-Centred Design: Reflections and new Directions. Human-Computer Interaction in the New Millennium. In Carroll (Ed.) ACM Press, New York: Addison-Wesley, 2001, 605-626.

18. T. Roselli, Artificial Intelligence Can Improve Hypermedia Instructional Technologies for Learning. ACM Computing Surveys, vol. 27, no. 4, Dec. 1995, pp. 624-626.

19. Roselli, T., Faggiano, E., Rossano, V., A Further Investigation On The Effectiveness Of A WWW Hypermedial System For Cooperative Learning. In Proceedings of International Conference on Computer in Education (ICCE2003) (Hong Kong, Cina, December 2003), 2003, pp 440-442.

20. Roselli, T., Faggiano, E., Grasso, A., Rossano, V., A Platform for Building and Using Personalized Courseware. In Proceedings of E-Learn 2003: World conference on E Learning in Corporate, Government, Healthcare, \& Higher Education (Phoenix, Arizona USA, November 2003), 2003, pp. 141-144.

21. Roselli, T., Faggiano, E., Grasso, A., Pragnell, M.V., A formal model for developing elearning software, In Proceedings of IEEE International Convention (Mipro2003) (Opatija, Croatia, May, 2003), 2003, pp. 70-74.

22. Soloway, E., Jackson, S.L., Kleim, J., Quintana, C., Reed, J., Spitulnik, J., Stratford, S.J., Studer, S., Eng, J., and Scala, N., Learning Theory in Practice: Case Studies in Learner-Centered Design. In Proceedings of the SIGCHI Conference on Human Factors in Computing Systems (CHI'96) (Vancouver, British Columbia, Canada, April 1996). ACM Press, New York, NY, USA, 1996, 189-196.

23. Somervell, J., Wahid, S. and McCrickard, D.S., Usability Heuristics for Large Screen Information Exhibits. In Proceedings of Human-Computer Interaction (Interact '03) (Zurigo, Svizzera, Sep. 2003), 2003, 904-907.

24. Stephanidis C., Akoumianakis D., Sfyrakis M., Paramythis A., Universal accessibility in HCI: Process-oriented design guidelines and tool requirements. Long Paper of the 4th ERCIM Workshop on "User Interfaces for All", Stockholm, Sweden, 19-21 October 1998. 